\title{
Assessment of Nerve Injuries after Surgical Removal of Mandibular Third Molar: A Prospective Study
}

\author{
Vikas Sukhadeo Meshram, ${ }^{1}$ Priyatama Vikas Meshram, ${ }^{2}$ and Pravin Lambade ${ }^{1}$ \\ ${ }^{1}$ Department of Oral and Maxillofacial Surgery, Swargiya Dadasaheb Kalmegh Smruti Dental College and Hospital, \\ Road Hingna-Waddhamna, Hingna, Nagpur, Maharashtra 441110, India \\ ${ }^{2}$ Department of Conservative Dentistry and Endodontic, Swargiya Dadasaheb Kalmegh Smruti Dental College and Hospital, \\ Road Hingna-Waddhamna, Hingna, Nagpur, Maharashtra 441110, India
}

Correspondence should be addressed to Vikas Sukhadeo Meshram; drvikasm@gmail.com

Received 24 July 2013; Accepted 5 September 2013

Academic Editors: M. Kondo and M. Miscusi

Copyright (C) 2013 Vikas Sukhadeo Meshram et al. This is an open access article distributed under the Creative Commons Attribution License, which permits unrestricted use, distribution, and reproduction in any medium, provided the original work is properly cited.

\begin{abstract}
Although third molar extraction is a routinely carried out procedure in a dental set-up, yet it is feared both by the patient and the dentist due to an invariable set of complications associated with it, especially in the form of nerve injuries. Hence, prior to performing such procedures, it would be wise if the clinician thoroughly evaluates the case for any anticipated complications so that adequate preventive measures can be taken to minimize the traumatic outcomes of the procedure and provide maximum patient care, which would further save the clinician from any sort of litigation.
\end{abstract}

\section{Introduction}

Impacted teeth can be defined as those teeth whose normal eruption is prevented by adjacent tooth, overlying bone or soft tissue, malpositioning and lack of space in the arch, or other impediments. Impacted mandibular 3rd molar is one of the most common findings which is detected on routine dental checkup. However the patient seeks treatment whenever there is pain, swellings or another discomfort.

Although the overall complication rate is low and most complications are minor, third molar removal is so common that the population morbidity of complications may be significant. As such, efforts to limit intraoperative or postoperative complications may have a great impact in terms of enhancing patient outcome.

Impacted mandibular third molar teeth are in close proximity to the lingual, inferior alveolar, mylohyoid, and buccal nerves (Figure 2). During surgical removal, each of these nerves is at risk of damage, but the most troublesome complications result from inferior alveolar or lingual nerve injuries. The majority of injuries result in transient sensory disturbance but, in some cases, permanent paraesthesia (abnormal sensation), hypoesthesia (reduced sensation), or, even worse, some form of dysaesthesia (unpleasant abnormal sensation) can occur.

These sensory disturbances can be troublesome, causing problems with speech and mastication and may adversely affect the patient's quality of life. They also constitute as one of the most frequent causes of complaints and litigation [1].

\section{Material and Methods}

The prospective study data was collected from 147 patients visiting the Department of Oral and Maxillofacial Surgery, Swargiya Dadasaheb Kalmegh Smruti Dental College \& Hospital, Nagpur, for surgical extraction of impacted mandibular third molar. In this study, preoperative predictive variables were recorded with data record of name, age, gender, and type of impaction. Postoperative assessment was done after one week at the time of suture removal for paresthesia/anesthesia by questioning about tongue, chin, and lip sensibility and performing neurosensory tests like 2-point discrimination, pinprick, and light touch. Patients with neurosensory disturbance were followed up for six months. 


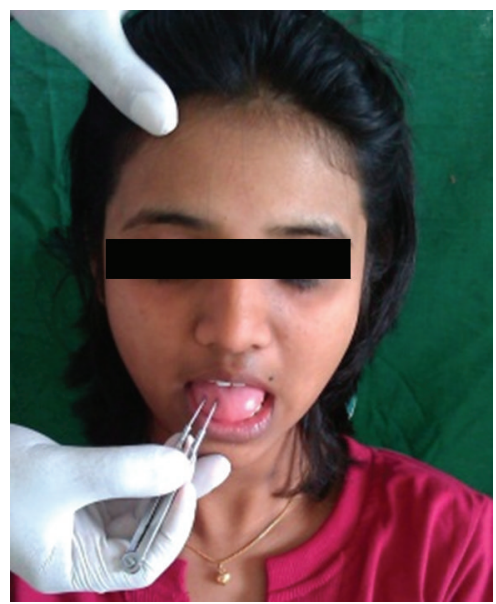

(a)

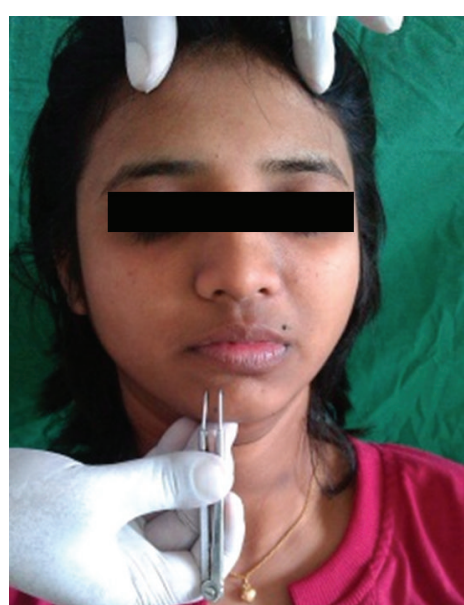

(b)

FIgure 1: Two-point discrimination test.

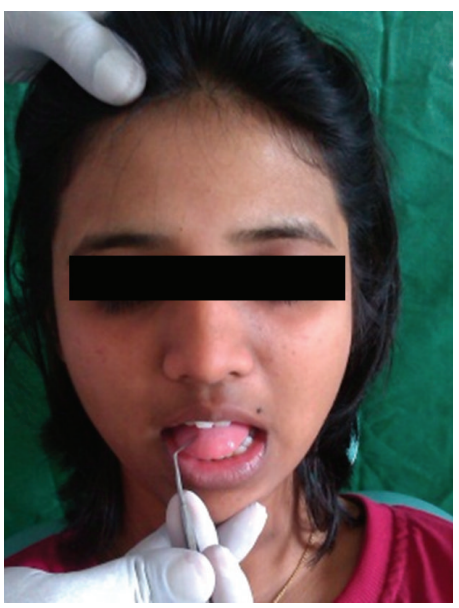

(a)

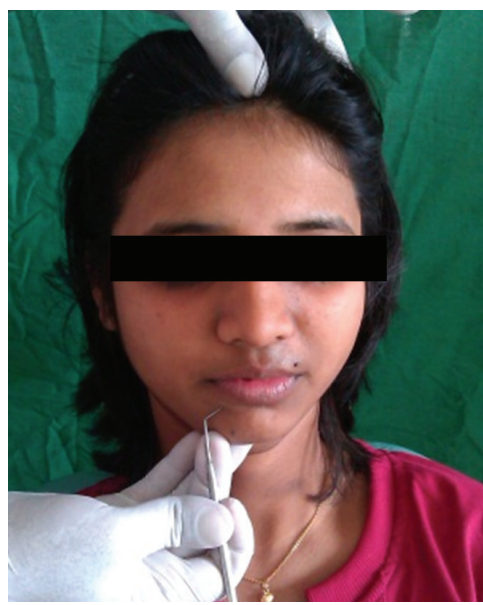

(b)

Figure 2: Pinprick test.

At the postoperative visit, each patient was specifically asked if there was any difference in sensation of lower lip or chin between operated and unoperated sides. Also specific questions were asked about accidental biting of lips, drooling/food running down the chin, and burning, painful, or tingling sensations.

Nerve injury assessment following clinical neurosensory tests was used. Before and during testing, the subject was asked to close the eyes and tests were performed [2].

2.1. Two-Point Discrimination Test (TPD). In this neurosensory test, the probes of caliper device were drawn across the surface of skin or mucosa at constant pressure and patient was asked whether one or two points are felt. One at a time blunt dual probes were applied to the skin or mucosa, and the subject was asked to raise his left hand if two points were sensed. The minimum separation that was consistently reported as two points was termed as two-point discrimination threshold. The separation distance at which the subject was capable of distinguishing two points in five or six trials was recorded for that particular zone. Whenever incorrect answers were given, the probe with the next large separation distance was selected. Whenever correct answers were given, probe with the next smaller separation distance was selected (Figure 1).

2.2. PinPrick Test (PP). In this test, a sharp dental probe was applied to the skin in a quick pricking movement and pain perception of the patient was assessed. Each test area was pricked three times bilaterally, and subject was asked if any difference was felt between the sides. Sensation was checked by pricking tongue, mucosa, lip, and skin over chin region. Paresthesia was defined as any postoperative change in sensitivity of tissues innervated by the trigeminal nerve after test evaluation (Figure 2). 


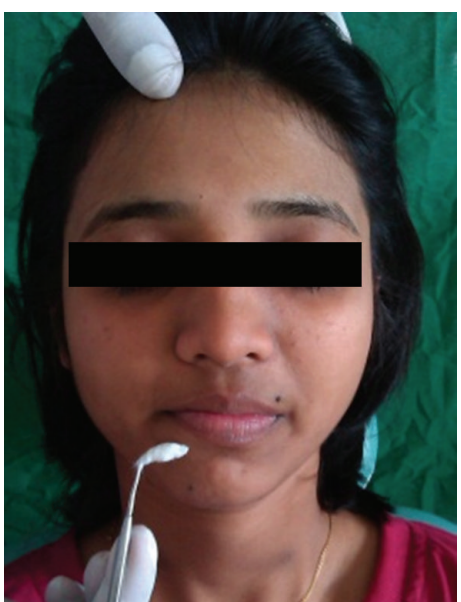

FIgURE 3: Light touch assessment.

2.3. Light Touch Assessment (LT). This method was used for testing by gently touching (tactile stimulation) the skin and evaluating the detection threshold of the patient. For this test, cotton stick was used to perform the test. Stimuli were applied at randomly and area of anesthesia was mapped by moving outward in small steps until stimulus is felt [2] (Figure 3).

\section{Results}

The prospective study data was collected from 147 patients visiting the department of Oral and Maxillofacial surgery, Swargiya Dadasaheb Kalmegh Smruti Dental College \& Hospital, Nagpur, for surgical extraction of impacted mandibular third molar.

Out of 147 patients, 95 were male patients and 52 were female patients. Patient's age ranged from 15 to 57 with mean of 26.3 years (Table 1). Out of total 147 patients, 62 (42.1\%) patients had mesioangular type of impaction, 37 (25.1\%) were horizontal, $36(24.4 \%)$ were vertical, $10(6.8 \%)$ patients had distoangular impaction, and $1(0.68 \%)$ patient each of linguoversion and inverted type of impaction (Table 2).

Lingual nerve paresthesia was reported in 2 patients (1.36\%) out of 147 cases, and the type of impaction was horizontal class II, position C and Disto-angular class II, position A. inferior alveolar nerve paresthesia was reported in 1 patient $(0.86 \%)$ having mesio-angular, class II, position A type of impaction (Table 3 ).

\section{Discussion}

The surgical removal of impacted mandibular third molars is one of the most commonly performed dentalveolar procedures in oral and maxillofacial surgery. Invariably, the surgeon may face various complications associated with the surgical removal of impacted mandibular 3rd molars, among which major postoperative complication is neurosensary deficit. It may affect either the inferior alveolar nerve or more commonly the lingual nerve that leads to numbness
TABLE 1: Gender distribution.

\begin{tabular}{lcc}
\hline Gender & $N$ & $\%$ \\
\hline Male & 95 & $64.6 \%$ \\
Female & 52 & $35.3 \%$ \\
\hline Total & 147 & $100 \%$ \\
\hline
\end{tabular}

TABLE 2: Angulations of 3rd molar impaction.

\begin{tabular}{lcc}
\hline Type of impaction & No. of patients & Percentage \\
\hline Mesioangular & 62 & $42.1 \%$ \\
Horizontal & 37 & $25.1 \%$ \\
Vertical & 36 & $24.4 \%$ \\
Distoangular & 10 & $6.8 \%$ \\
Linguoversion & 1 & $0.68 \%$ \\
Inverted & 1 & $0.68 \%$ \\
\hline
\end{tabular}

TABLE 3: Sample distribution of nerve damage complication.

\begin{tabular}{lccc}
\hline Nerve injury & Males & Females & Incidence \\
\hline Lingual nerve & 1 & 1 & $1.36 \%$ \\
Inferior alveolar nerve & 0 & 1 & $0.86 \%$ \\
\hline
\end{tabular}

of the ipsilateral anterior two-thirds of the tongue and taste disturbance [1].

In a landmark article by Howe and Poyton [3] in 1960, it was determined after evaluating 1,355 impacted mandibular molars clinically at the time of extraction and radiographically that a true relationship existed in approximately 7.5 percent. A "true relationship" was defined as the visualization of the neurovascular bundle at the time of tooth removal. An "apparent" relationship was defined by radiographs as a circumstance in which the roots of the teeth appeared to be in an intimate relationship to the IAN. This occurred in 61.7 percent of the teeth.

Of the 70 cases that developed postsurgical nerve impairment, over 50 percent of them had a true relationship which represented 35.64 percent incidence. This was a 13 times greater incidence than that occurring with those teeth exhibiting an apparent one. They further noted increased incidences in older patients: teeth that were deeply impacted, those which exhibited grooving, notching, or perforation, and a three- and four-time increase in mesial and horizontally impacted teeth with linguoversion [3].

In 1990, Rood and Nooraldeen Shehab [4], in a literature review, collected seven radiographic indicators of a close relationship between the impacted 3rd molar and the inferior alveolar canal. Four signs were observed in the tooth root (darkening, deflection and narrowing of the root, and a bifid root apex) and the other three in the canal (diversion, narrowing, and interruption in the white line of the canal) (Figure 4). The authors collected retrospective data on 553 patients and prospective data on 552, observing the appearance of some of the radiographic indicators of a close relationship between the impacted 3rd molar and the inferior alveolar canal in the OPG in $9.1 \%$ and $16.4 \%$ of cases, respectively. In the retrospective study, nerve damage was statistically 


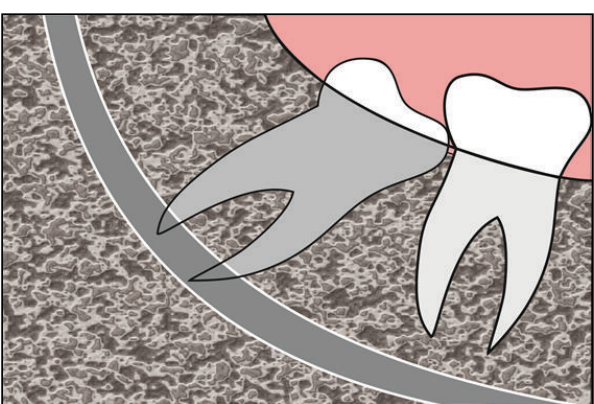

(a)

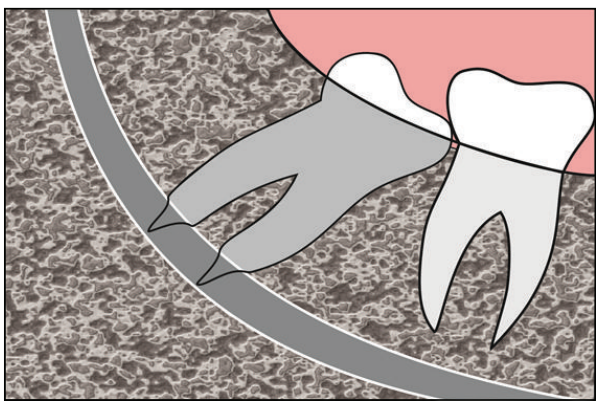

(c)

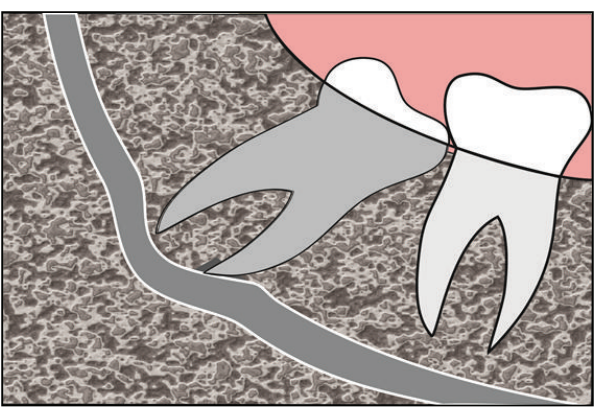

(e)

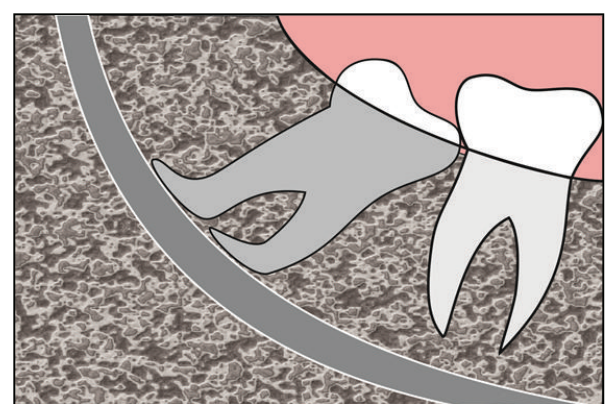

(b)

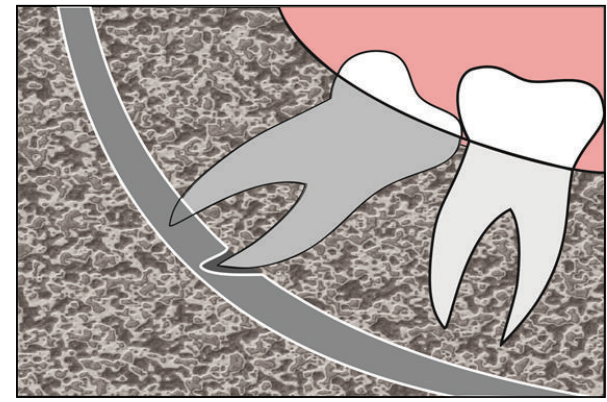

(d)

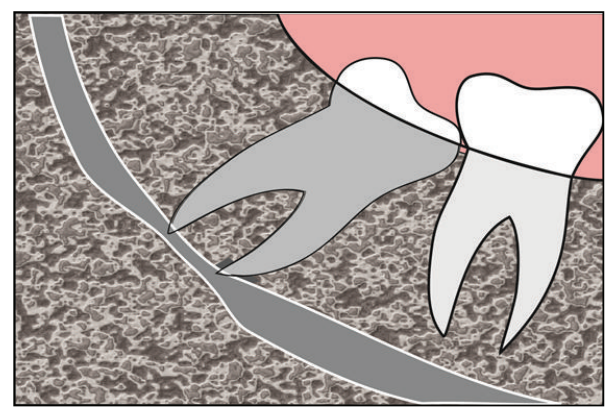

(f)

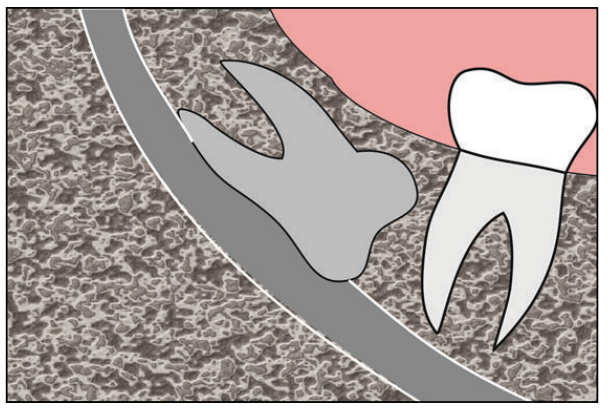

(g)

FIGURE 4: Relationship of inferior alveolar nerve with roots of impacted third molar. (a) Darkening of root. (b) Deflection of root. (c) Narrowing of root. (d) Bifid root apex. (e) Diversion of canal. (f) Narrowing of canal. (g) Interruption in white line of canal.

related to all the radiographic signs except bifid root apex and darkening of the canal. In the prospective study, nerve damage was related to diversion of the canal, followed by darkening of the root and interruption of the canal.

Unintended iatrogenic injury to the lingual nerve may happen during third molar surgery due to the anatomical proximity of the cortex region of the molar to the nerve, being separated from it by the periosteum alone (Figure 5).

Although the symptoms may resolve with time in most of the cases, an estimation of the type of injury has to be made to establish the treatment plan and allow recovery. Judgment can be made based on various systems for classification of 


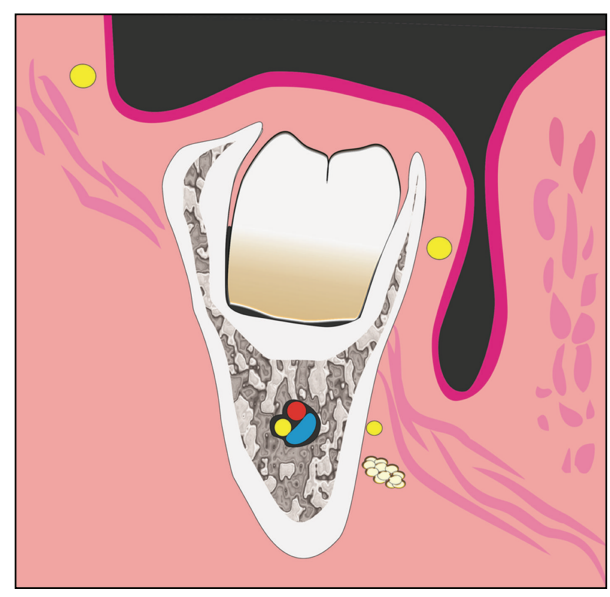

FIGURE 5: Vital structures in relation to the impacted 3rd molar.

nerve injuries, first among which to be introduced in 1943 was Seddon's classification that involves the following three categories.

(1) Neuropraxia. It is an interruption in conduction of the impulse down the nerve fiber. The recovery in such cases takes place without Wallerian degeneration, and, hence, it is considered to be the mildest form of nerve injury.

(2) Axonotmesis. It is loss of the relative continuity of the axon and its covering of myelin, but preservation of the connective tissue framework of the nerve.

(3) Neurotmesis. It is loss of continuity of not only the axon, but also the encapsulating connective tissue [5-7].

Another system was given by Sunderland in 1951 [5] which includes five classes as follows.

First Degree. It is similar to Seddon's neuropraxia and due to compression or ischemia, a local conduction block and focal demyelinization occur which recovers in 2-3 weeks.

Second Degree. It is similar to Seddon's axonotmesis and recovery occurs at the rate of $1 \mathrm{~mm} /$ day as the axon follows the "tubule."

Third Degree. In this class, the endoneurium gets disrupted while the epineurium and perineurium remain intact. Recovery may range from poor to complete and depends on the degree of intrafascicular fibrosis.

Fourth Degree. In this class there is an interruption of all the neural and supporting elements although the epineuriumis intact and the nerve becomes usually enlarged.

Fifth Degree. This class involves a complete transection of the nerve with the loss of continuity [5-7].

Most studies have shown that if the paresthesia follows extraction, it is likely to be temporary and to be resolved within the first 6 months. However, if no improvement is seen after 2 years of followup, the altered sensation is likely to represent nerve dysfunction that may be in the form of permanent neurosensory disability, a complete loss of sensory function, and neurogenic symptoms $[8,9]$. Nevertheless, it seems that compression should not cause anesthesia for more than 4 months and sectioning should not cause anesthesia for more than 8 months. Anesthesia without improvement after 1 month is also very likely to leave some permanent residual impairment. The variable rate of recovery and improvement in symptoms could be explained by the fact that IAN or LN injuries differ in type. The lesions that recover within the first 3 months are probably neurapraxias or Sunderland first- or second-degree injuries, which are more common, and longstanding injuries could represent more severe axonotmesis or Sunderland third- or even fourth-degree injuries. Delayed recovery from IAN injuries after more than 1 year has also been reported in the literature.

The incidence of reported postoperative dysaesthesia of the inferior alveolar and the lingual nerve varies widely in the studies published so far. In a study published in 2000 by Gargallo-Albiol et al., the incidence of temporary disturbances affecting the IAN or the LN was found to be in the range from $0.278 \%$ to $13 \%$ [2].

In another study by Zuniga, the incidence of permanent injury to the IAN and LN has been mentioned to fall in the range between $0.4 \%$ and $25 \%$ and $0.04 \%$ and $0.6 \%$, respectively [10]. Tay and Go carried out a study in 2004 to determine the incidence of inferior alveolar nerve paraesthesia in those patients where an exposed inferior alveolar nerve bundle is seen during third molar surgery, and it was concluded that such a situation hints a high probability of an intimate relationship of the nerve with the tooth and carries a $20 \%$ risk of paraesthesia with a $70 \%$ chance of recovery by one year from surgery [11].

Recently Cheung et al. carried out a study in which it was seen that of all the lower third molar extractions performed by various grades of operators, $0.35 \%$ developed IAN deficit and $0.69 \%$ developed LN deficit. It concluded that distoangular impaction was found to increase the risk of LN deficit significantly, wherein the depth of impaction was related to the risk of IAN deficit. On the other hand, sex, age, raising of a lingual flap, protection of LN with a retractor, removal of distolingual cortex, tooth sectioning, and difficulty in tooth elevation were not found to be significantly related to IAN or LN injury [12].

The study of Anwar Bataineh showed postoperative lingual nerve paresthesia that occurred in $2.6 \%$ patients. There was a highly significant increase in the incidence associated with raising of a lingual flap. The incidence of inferior alveolar nerve paresthesia was 3.9\%. The results of this study concluded that the elevation of lingual flaps and the experience of the operator are significant factors contributing to lingual and inferior alveolar nerve paresthesia, respectively [13].

Considering angulation of third molars in our case series, teeth with mesial angulations were reported in $42.1 \%$, horizontal angulation in $25.1 \%$, vertical angulation in $24.4 \%$ and distoangulation in $6.8 \%$, one case each of lingual version and inverted is also noted. 
The depth of the impacted mandibular third molar and its lingual angulation are other factors which may affect the probability of nerve damage occurring. Eduard ValmasedaCastellón et al. carried out a study to assess the risk of lingual nerve injury after surgical removal of lower third molars and concluded that anatomical factors such as lingual angulation of the third molar, surgical maneuvers such as retraction of the lingual flap, or vertical tooth sectioning, and surgeon inexperience all increase the risk of lingual nerve damage, although permanent lesions seem to be very rare [12].

In our study, out of total 147 patients, 2 patents reported with lingual nerve paresthesia (1.36\%) which having horizontal class II, position C and Disto-angular class II, position A type of impaction and 1 patient were of inferior alveolar nerve paresthesia having mesio-angular, class II, position A type of impaction.

Various factors are responsible for the injury to the inferior alveolar nerve and lingual nerve in third molar surgery. In our study, incidence of injury to IAN and LN was comparatively very low, and all cases were of transient paresthesia. All the precautions should be taken to prevent the injury to the inferior alveolar nerve or lingual nerve.

\section{Conclusion}

Mandibular third molar extraction is a very commonly carried out procedure in day-to-day dental practice and is undoubtedly associated with few risks especially neural injuries and therefore in the light of the existing evidence, adequate preoperative evaluation of the patient and meticulous surgical technique with minimum handling of the lingual flap are of paramount importance to diminish the incidence of nerve injury.

Although third molar surgery is a secure and low morbidity procedure, the risk of complications will always exist and it increases with increased surgical difficulty; hence, the patient should always be educated about the risks and benefits of surgery in order to ensure adequate surgical management of impacted mandibular third molar.

\section{Acknowledgment}

The authors are grateful to Dr. Anisha Maria Madam for assistance in the design of the study, Professor and HOD, department of Oral and Maxillofacial Surgery, Rishiraj Dental College and Hospital, Bhopal, India.

\section{References}

[1] R. Sharma, A. Srivastava, and R. Chandramala, "Nerve injuries related to mandibular third molar extractions," E-Journal of Dentistry, vol. 2, no. 2, 2012.

[2] J. Gargallo-Albiol, R. Buenechea-Imaz, and C. Gay-Escoda, "Lingual nerve protection during surgical removal of lower third molars: a prospective randomised study," International Journal of Oral and Maxillofacial Surgery, vol. 29, no. 4, pp. 268271, 2000.
[3] J. Howe and H. Poyton, "Prevention of damage to the inferior alveolar dental nerve during the extraction of mandibular third molars," British Dental Journal, vol. 109, article 355, 1960.

[4] J. P. Rood and B. A. A. Nooraldeen Shehab, "The radiological prediction of inferior alveolar nerve injury during third molar surgery," British Journal of Oral and Maxillofacial Surgery, vol. 28, no. 1, pp. 20-25, 1990.

[5] S. Sunderland, "A classification of peripheral nerve injuries producing loss of function," Brain, vol. 74, no. 4, pp. 491-516, 1951.

[6] K. Andrew and L. Churchill, "Classification of nerve injuries," Essential Neurosurgery, pp. 333-334, 1991.

[7] M. S. Greenberg, Injury Classification System, Handbook of Neurosurgery, 3rd edition, 1994.

[8] D. T. Wofford and R. I. Miller, "Prospective study of dysesthesia following odentectomy of impacted mandibular third molars," Journal of Oral and Maxillofacial Surgery, vol. 45, no. 1, pp. 15-19, 1987.

[9] T. P. Osborn, G. Frederickson Jr., I. A. Small, and T. S. Torgerson, "A prospective study of complications related to mandibular third molar surgery," Journal of Oral and Maxillofacial Surgery, vol. 43, no. 10, pp. 767-769, 1985.

[10] J. R. Zuniga, "Management of third molar-related nerve injuries: observe or treat?" Alpha Omegan, vol. 102, no. 2, pp. 79-84, 2009.

[11] A. B. G. Tay and W. S. Go, "Effect of exposed inferior alveolar neurovascular bundle during surgical removal of impacted lower third molars," Journal of Oral and Maxillofacial Surgery, vol. 62 , no. 5, pp. 592-600, 2004.

[12] L. K. Cheung, Y. Y. Leung, L. K. Chow, M. C. M. Wong, E. K. K. Chan, and Y. H. Fok, "Incidence of neurosensory deficits and recovery after lower third molar surgery: a prospective clinical study of 4338 cases," International Journal of Oral and Maxillofacial Surgery, vol. 39, no. 4, pp. 320-326, 2010.

[13] A. B. Bataineh, "Sensory nerve impairment following mandibular third molar surgery," Journal of Oral and Maxillofacial Surgery, vol. 59, no. 9, pp. 1012-1017, 2001. 

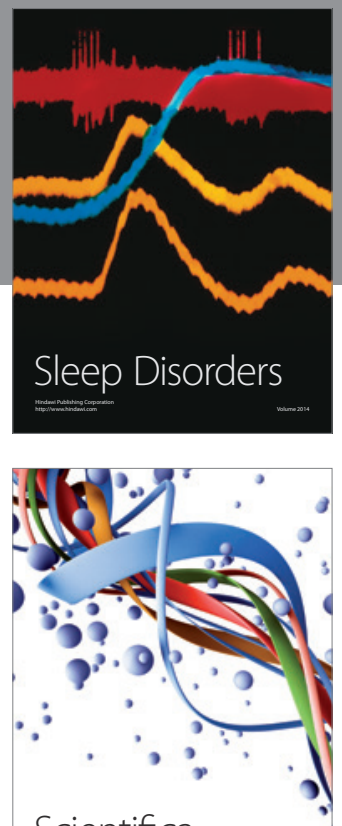

Scientifica
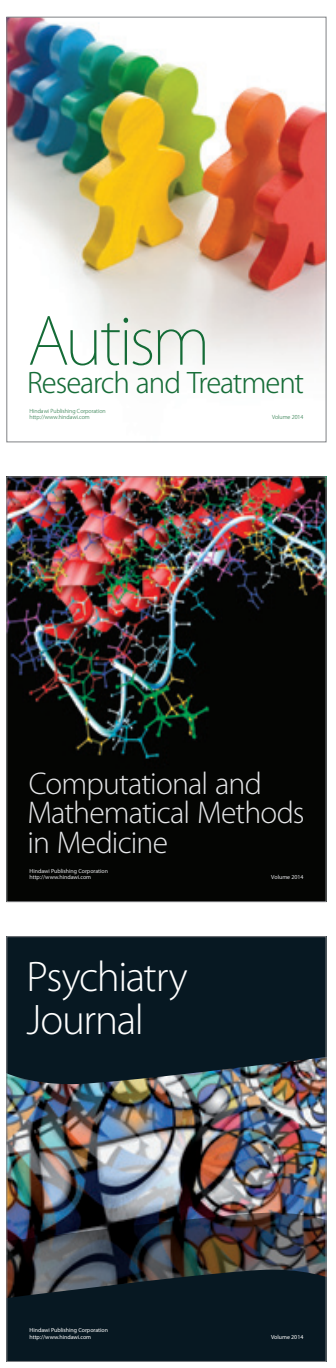
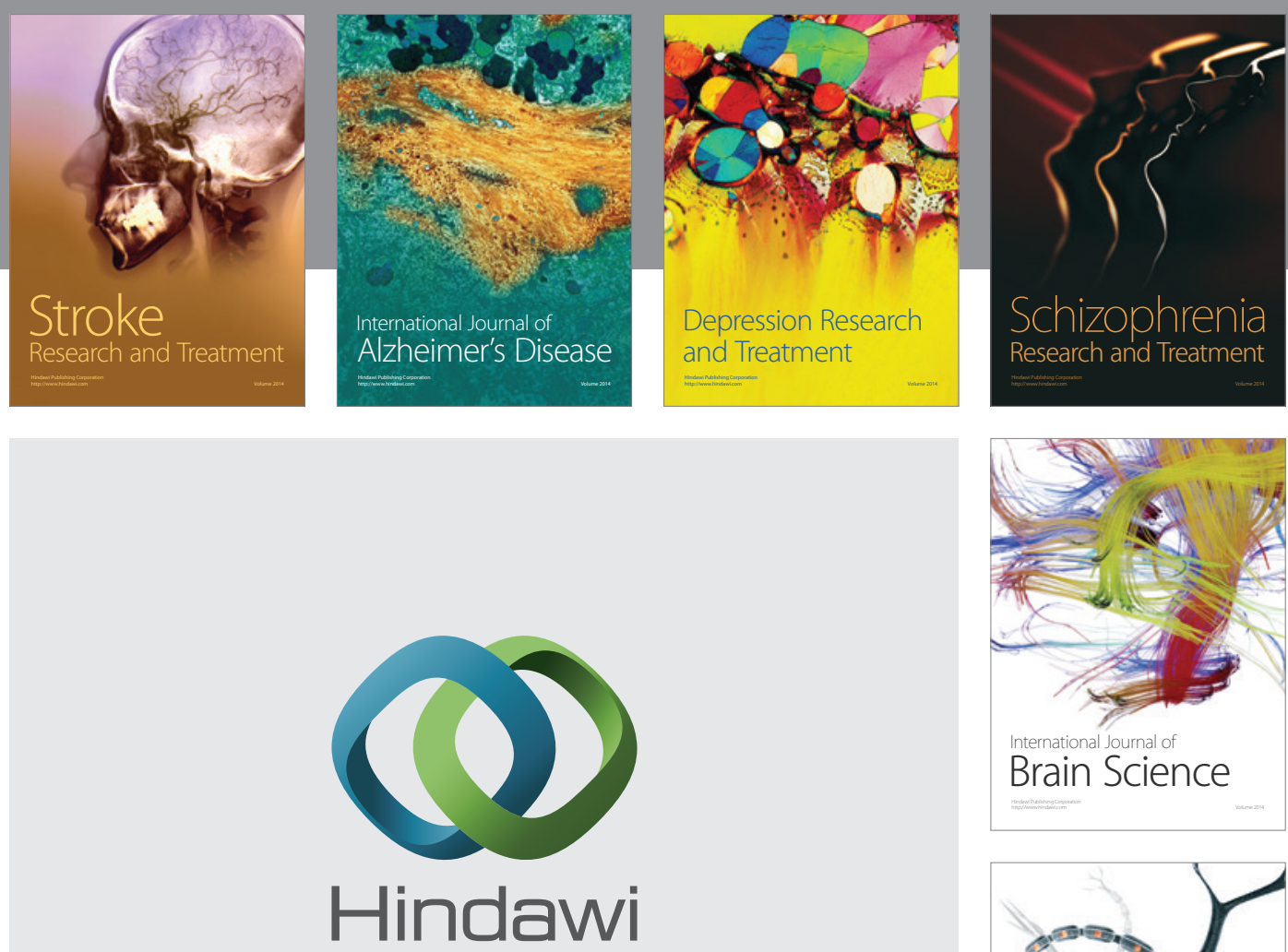

Submit your manuscripts at

http://www.hindawi.com
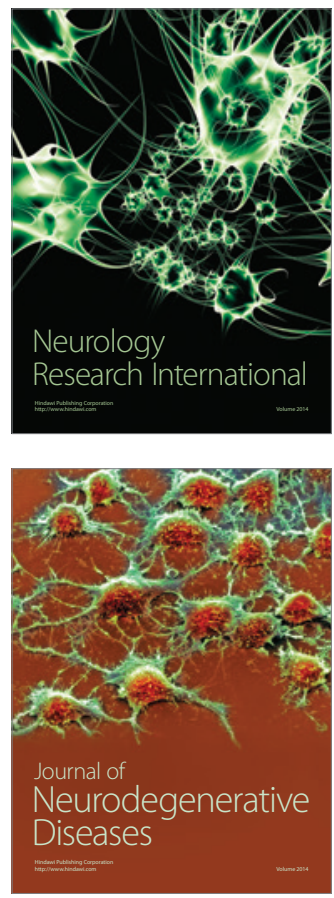

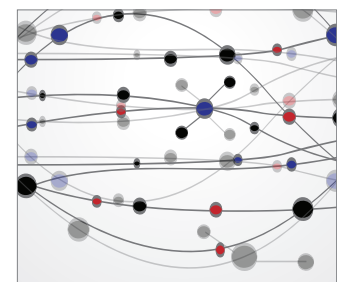

The Scientific World Journal
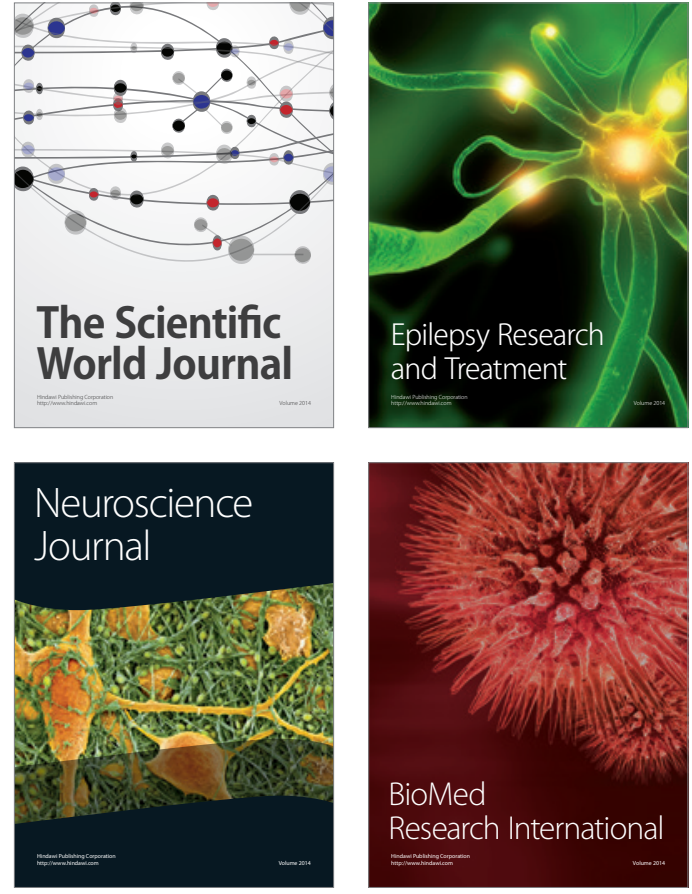

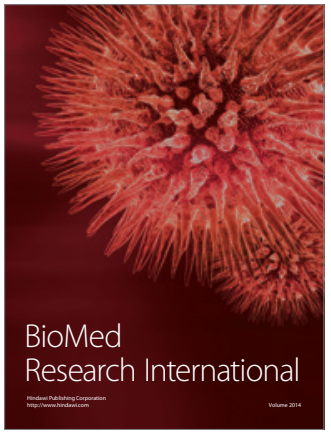

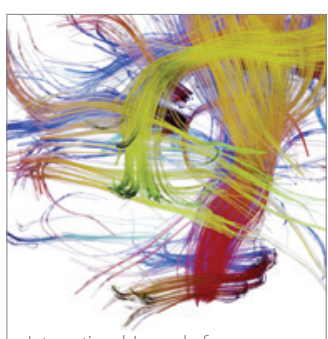

Brain Science

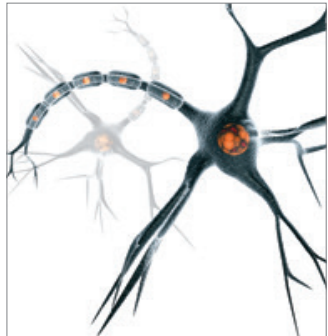

Neural Plasticity
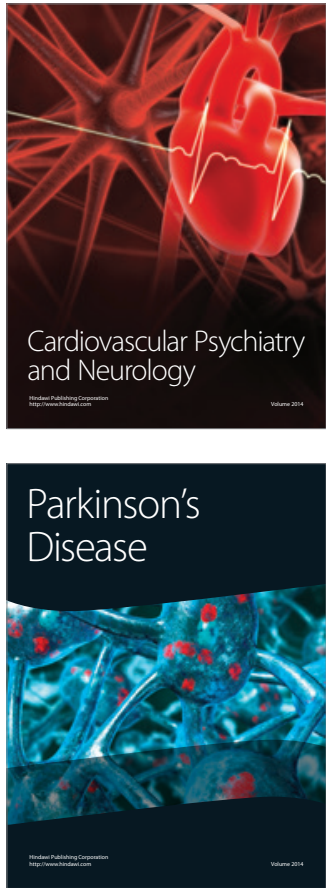